sive, give the book a distinctive flavour which fully justifies its publication. A notable feature is the treatment of the "Gauss problem", determining an orbit from two (radar) positions and times, a reminder that the USAF has the uncomfortable task of identifying the Earth impact points of all objects sighted by radar. The solution of Kepler's equation is also fully discussed, with emphasis on the use of "universal variables" which are valid for both the ellipse and the hyperbola: this bias is logical, too, for newly-sighted objects do not carry placards advertising their eccentricities. Other chapters cover ballistic missile trajectories and interception; Iunar trajectories, with emphasis on the useful patched-conic approximation; and interplanetary transfer orbits, including the problems of plane-changing. There is also a section on space surveillance, giving the most detailed account yet published of the USAF tracking network.

The layout of the book has obviously been considered with care, and the general appearance is pleasing: the diagrams are well drawn; many of the symbols are clean and elegant in design; and it is useful to have rectangles enclosing the most important equations, though traditionalists may wince. Unfortunately, however, the detailed printing of the mathematics is not far short of a typographical disaster. Hundreds of corrections are needed where symbols run together, suffixes are unlowered, diagrams and text are inconsistent, alignments are incorrect or spacing excessive. Worst of all are the minus signs: a good healthy minus, about $2 \mathrm{~mm}$ long, graces the early pages of the book; but on page 115 we meet a mini-minus, about $600 \mu \mathrm{m}$ long, and difficult to distinguish from a dot. After a running battle lasting about sixty pages, the mini-minus finally ousts the mega-minus, to the dismay of all but short-sighted readers. The units are as mixed as the minus signs, and readers need to be alert to recognize that $\mathrm{km}$ signifies kilometres but $\mathrm{nm}$ stands for nautical miles. In spite of these typographical troubles, the text is very readable, being written in a pleasant style, with some interesting historical digressions.

D. G. KING-HeLE

\section{DNA and All That}

The New Biology. By Graham Chedd. Pp. xiv +306 . (Basic Books: New York, 1972.) \$7.50.

"The New Biology" has come to describe the approach to living systems at the molecular level which has proved so successful in the past decade, not just in molecular genetics but also in cell biology, immunology and neurobiology.
These are the topics discussed in Graham Chedd's new book, which takes a narrative approach to this subject. The style and level of discussion may fairly be termed "popular" although the content of the book seems to be intended for students somewhere between school and university.

The first part of the book is concerned with the development of modern genetics, the discovery of the genetic role and structure of DNA, and the synthesis of nucleic acids and proteins. This is well written, with its emphasis on the personalities involved and their key experiments, and provides a straightforward account of the development of molecular biology. The book is written largely post hoc ergo propter hoc and an air of ineluctable discovery accompanies much of the discussion.

The next section of the book discusses the structure and evolution of proteins and again provides a history of the successful experiments performed on the structure of macromolecules. Any errors in the first part of the book tend to be minor and of emphasis rather than in fact, although the unwatchful reader may on occasion be misled by the author's habit of presenting conclusions two or three pages before the important qualifications which should be attached to them.

The discussion of more recent research into control mechanisms in bacteria and in higher organisms is on less sure ground. Too much emphasis is placed on translational control and there are some misleading comments on allosteric regulation of enzyme activity and on transcriptional controls in bacteria. Chedd's enthusiasm for sigma factors as control proteins, however, and his acceptance of Bonner's experiments with chromosomal RNA may perhaps seem uncritical only as the result of events which have taken place since the book was written.

The account of cellular research in higher organisms is more compressed than the discussion of molecular bio$\operatorname{logy}$; and the sense of perspective which is to be found in the early part of the book is missing later. The final chapters are concerned with cancerand in particular with tumour viruses -ageing and the brain. Much of the discussion in the later parts of the book is too brief to do justice to its subject matter, especially the last section on the brain.

Narrating the future is no easy task and the personal narrative approach is less successful when used to project future trends than when applied to history. That "Watson is personally convinced that the work presently being done on polyoma and SV40 will produce a molecular understanding of cell transformation within the next five or ten years" may be interesting; but it would be more useful if the author were to tell us what conclusions he himself draws from his previous discussion and why.

The main emphasis of the book lies, in spite of its title, in classical molecular biology. Indeed, for a readable account of the crucial experiments in molecular biology, this is a useful book for the beginner and Chedd has fulfilled his principal objective, telling a simple story concisely and accurately. Discussion is at its weakest on very recent research and future trends; the attempt to make the book very topical has perhaps proved too difficult. The first part of the book, again, may be interesting to the layman, but the subsequent chapters are likely to prove too complex. Although the index is adequate, the surprising lack of any bibliography must restrict its use for the student.

BENJAMIN LEWIN

\section{Ice Age Geology}

Glacial and Quaternary Geology. By Richard Foster Flint. Pp. xii +892. (Wiley: New York and London, June 1971.) £10.95.

Glacial and Quaternary Geology by Richard Foster Flint sums up his view of the subject on his retirement after a lifetime spent studying this field. As a work of synthesis, the volume represents a remarkable achievement both in the breadth of its coverage and for the selectivity with which the author has, over the years, sifted and evaluated contributions from the various specialized fields which relate to his general study of the Quaternary.

Since the publication in 1957 of his earlier general work Glacial and Pleistocene Geology, substantial advances have been made in a number of fields due to the developing use of techniques such as ${ }^{11} \mathrm{C}$ and $\mathrm{K} / \mathrm{Ar}$ dating, coring of the ocean bed and of ice sheets, and the use of oxygen isotopes to study climatic history. Flint claims that the present volume contains about 80 per cent new material, and a comparison with his earlier book bears this out. The bibliography, for example, has increased from 34 to 63 pages and spot checks of 200 references show that 63 per cent are to papers which appeared since his 1957 volume was written. A check of 100 references in that volume showed that about half had been dropped in the new volume, including half the references to his own earlier work. As a guide through the literature of a vast and complex subject, the present volume, at once comprehensive and discriminating, is invaluable.

The book is, however, more than a review of its subject. It is also a text- 